\title{
Serious motor vehicle collisions involving young drivers on Norwegian roads 2013-2016: Speeding and driver-related errors are the main challenge.
}

\begin{abstract}
Objective: Motor vehicle collisions (MVCs) are a leading cause of death and acute disability among young adults worldwide. We performed a prospective study of young drivers involved in severe MVCs, investigating the critical events leading up to a collision with an emphasis on driver-related factors and collision culpability.
\end{abstract}

Methods: A study was conducted in southeastern Norway of all drivers younger than 25 years who were involved in high-energy MVCs resulting in immediate hospitalization during 2013-2016. Collision investigators evaluated the exterior and interior of the motor vehicle (MV) within $24 \mathrm{~h}$. Complementary information was obtained from interviews of collision victims, ambulance personnel and witnesses, from police reports, and medical records.

Results: There were 145 young drivers included during a 3-year study period, representing an estimated incidence of 29 per 100,000 drivers with registered driving licenses. Ninety-two percent (133/145) were considered culpable of initiating the MVC, and only $2 \%$ of the critical factors preceding the collision were not related to the driver. There were $74 \%(108 / 145)$ males, the median MV age was 14 years, and $86 \%(125 / 145)$ of the MVs were passenger cars. The MVCs predominantly occurred on rural roads $(90 \%, 130 / 145)$. Among the culpable drivers, speeding behavior was the main predisposing factor in $80 \%(106 / 133)$ of the collisions. Driving at excessive speed was associated with single-vehicle collisions $(87 \%, 74 / 85)$ and the presence of passengers $(89 \%, 56 / 63)$. Compared to nonculpable drivers, culpable drivers were more often younger than 21 years $(66 \%$ vs $33 \%, p=0.031)$, had obtained their license less than 2 years previously ( $68 \%$ vs $20 \%, p=0.004)$, and were more likely to have been drinking or using drugs $(27 \%$ vs $0 \%, p=0.039)$. The overall rate of seatbelt use was $79 \%(114 / 145)$.

Conclusion: The vast majority of injury-causing MVCs involving young drivers are initiated by those drivers. These incidents are characterized by male drivers with little driving experience who are operating old cars on rural roads at excessive speeds. Driving under the influence of alcohol or drugs is also not uncommon. These issues should be targeted in future preventive measures.

Keywords: Driver behavior; young drivers; DUI; speeding; serious injury; collision investigation; self-report 


\section{Introduction}

Motor vehicle collisions (MVCs) represent a leading cause of early deaths worldwide (WHO 2018). Young adults (16-24 years of age) are especially at risk, and constituted 30\% of all serious and fatal injuries in MVCs in Norway between 2000 and 2012 (Statistics-Norway). The elevated collision risk for younger drivers has been predominantly attributed to their lack of driving experience and poor driving skills (McKnight and McKnight 2003; McCartt et al. 2009). Others have pointed out that young males are prone to sensation-seeking behaviors such as speeding and hazardous driving (Simons-Morton, Lerner, and Singer 2005). On the road, young drivers may not only pose a risk to themselves but also endanger the safety of their passengers and other road users.

Most studies of young adults involved in MVCs have had retrospective designs, relying on databases, secondarydata analysis of police reports, or the use of questionnaires and hence have obvious limitations. These limitations include data having not been collected systematically, underreporting, and self-reporting, thereby reducing the accuracy of responses and resulting in recall biases. Also, several changes related to traffic safety have occurred in recent decades, such as the development of safer vehicles and improved road standards as well as a greater focus on education and driving behavior. How these aspects affect young drivers to cause or be involved in severe MVCs has not been fully investigated.

We undertook a prospective cross-sectional study that investigated in-depth young adults involved in highenergy MVCs resulting in immediate hospitalization of the driver or any of the vehicle occupants. The collision scene was investigated, witnesses and occupants were interviewed, interdisciplinary data were collected, and all data were assessed on a case-by-case basis. The interdisciplinary data collection made it possible to assess collision culpability. This is a valuable addition in the MVC research in determining the factors contributing to the chain of events preceding a collision.

In this study we focused on the drivers and the circumstances associated with the collision. The goal was to elucidate the critical events preceding serious MVCs involving young drivers with emphasis on drivercharacteristics and collision culpability, and provide updated data for facilitating future prevention strategies.

\section{Materials and Methods}

\section{Investigation protocol}

Data in this prospective cross-sectional study of youth occupants involved in high-energy MVCs were collected from March 2013 to March 2016 in southeastern Norway. This area covers a population of approximately 3.0 million and consists of both urban and rural environments. Approximately 256,000 of the populace are aged 18 24 years, of which 64\% have a registered driving license (Nordbakke, Sagberg, and Gregersen 2016).

Three collision investigators with training and experience from a similar study of child occupants in MVCs (Skjerven-Martinsen et al. 2014), were on call throughout the study period, and were alerted by the regional Emergency Medical Communication Centers (EMCCs).

In the event of a high-energy MVC involving occupants in the 16-24 year age group with possibly severe or fatal injuries, and at least one of the occupants (driver or not) within the motor vehicle MV was met by a trauma team in the admitting hospital, the investigation team started the process of collecting data. This dataset provided the basis for two different studies. Included in the present study were only drivers aged 16-24 years involved in high-energy MVCs resulting in serious occupant injury.

If the case was enrolled in our study, a collision investigator was dispatched to the collision scene within $24 \mathrm{~h}$ of the MVC to investigate the involved MVs. The collision investigators interviewed the involved occupants, witnesses and emergency personnel, followed by an investigation of the vehicle either on-site or at a service station.

The on-scene investigations were supplemented by information obtained from the involved occupants, emergency medical service personnel, witnesses, EMCC reports, and police reports. Consent was either given 
from the occupants involved if they were able to do so or from the closest person/family of the occupant if he/she was unconscious/intubated/fatally injured. After informed consent was obtained, relevant medical records or autopsy files were collected. To further explore the characteristics of the MVCs, youth drivers who were alive and able to cooperate were interviewed within 2 weeks after the collision. They were asked to fill out a questionnaire form with questions regarding their driving experience, the purpose and mileage of the current trip, a self-reported explanation of the collision, the use of cell phones while driving, and drowsiness/fatigue while driving.

\section{Subjects}

The subjects investigated were drivers younger than 25 years involved in high-energy collisions (Figure A1 in the online appendix). In Norway, a driving license can be obtained at the age of 18, however unlicensed driving among 16- and 17-year-olds are not exceptional and therefore drivers of this age were also included in this study.

\section{Definition of variables}

The following information was registered:

- Driver sex, age, height, BMI, and seatbelt usage.

- Results of toxicology analyses.

- Injury severity using the Abbreviated Injury Scale (AIS) 2005 manual (Association for the Advancement of Automotive Medicine, 2008). Collision location (rural or urban), collision type and impact (one impact did not mutually exclude another impact), road type, speed limit, MV speed, weather conditions, time of day, year, and MV characteristics (type, weight, model year/age/manufacturer, and presence of safety devices).

The speed at which the MV was traveling just before the collision was estimated by reconstructing the course of events, by looking at the road surface and braking tracks, and studying the external and internal vehicle damage. The principal direction of force and the instantaneous change in velocity $(\Delta V)$ were calculated manually in collaboration with an experienced technical collision investigator. Statements from drivers, passengers, and eyewitnesses completed the picture. Furthermore, speeding was categorized into whether the driver was exceeding the posted speed limit, was driving too fast for the conditions (e.g., too fast for the radius of a curve), or driving hazardously (e.g., hazardous overtaking or not keeping a sufficient distance from the vehicle in front).

\section{Culpability analysis}

Responsibility levels in the collision were determined by an established scale (Robertson and Drummer 1994), with adaptations suggested by Brubacher et al. (Brubacher, Chan, and Asbridge 2012). Based on the circumstantial information available, we scored factors (e.g., driving conditions, speeding and driving maneuvers, contributions by other parties, type of collision, witness observations) reflecting the level of mitigation from 1 (unfavorable) to 4 (mitigating/favorable). Driver errors such as absentmindedness, fatigue and observation failure may all precede aberrant driving behavior that results in culpability for a collision, despite no misconduct having taken place from a legal perspective. Culpability was therefore assigned based on consideration of whether a collision was avoidable rather than on whether the driver obeyed traffic laws. Low scores suggested absence of external factors indicating that the driver contributed to the crash. A driver with an aggregate score of 12 or less was deemed culpable. If a sufficient number of mitigating factors from the sum total of the scores were identified a driver would be considered either partly (with a score of 13 or 14) or totally exonerated from blameworthiness, i.e., nonculpable (with a score of $\geq 15$ ). Scores of 13 and 14 were considered intermediate, that is, unclear whether the driver or the circumstances played the larger role in the collision. Intermediate cases were identified, discussed and we arrived at a consensus opinion for all collisions; if more than two mitigating factors were present, the driver was exonerated fully from culpability.

\section{Toxicology}

Analysis data on the consumption of alcohol and medicinal and illicit drugs obtained from hospital records or police reports were included. The threshold level for likely impairment was a blood alcohol concentration (BAC) of $\geq 0.5 \mathrm{~g} / \mathrm{kg}$, or a concentration equivalent to a BAC of $\geq 0.5 \mathrm{~g} / \mathrm{kg}$ for psychoactive medicinal substances or illicit drugs. However, blood tests were not performed consistently, and in some cases the medical records indicated 
obvious signs of alcohol consumption or drug influence. Health care takers' description of observed behavior, findings from the physical examination (alcoholic odor), or findings of alcoholic beverages in the MV then lead to suspicion of impairment without blood toxicology.

\section{Data analyses}

Chi-square and Fisher's exact tests were used for univariate analyses of differences in baseline characteristics and collision-related circumstances between culpable and nonculpable drivers, as well as to explore and identify collision-related associations among culpable drivers only. The conventional significance cutoff level of $5 \%$ was used in the statistical analyses performed with SPSS statistical software (version 24.0, IBM Corporation, Armonk, NY). The annual incidence of serious injury-causing collisions involving a driver 18-24 years of age was derived by dividing the total number of serious injury-causing collisions detected per year in the study with the number of registered drivers of this age group $(164,000)$ (Nordbakke, Sagberg, and Gregersen 2016).

\section{Ethics}

The study was approved by the Regional Committee for Medical and Health Research Ethics and the Norwegian Prosecuting Authority. Informed consent was obtained from all cases. In the case of a minor younger than 18 years or a fatality, consent was obtained from their next of kin.

\section{Results}

During the 3-year study period, data on 163 MVs with at least 1 occupant aged 16-24 years involved in seriousinjury causing MVCs were registered, of which 18 were chauffeured by drivers $\geq 25$ years and thus excluded. The characteristics of the drivers of the included $145 \mathrm{MVs}$ are presented in the online appendix. Four of the 145 drivers were younger than 18 years and hence driving illegitimately, whereas the drivers in the 18-24-year age group were licensed. A frequency of 141 drivers aged 18-24 years involved in serious injury-causing collisions during the study period indicates an annual incidence of 29 per 100,000 drivers with registered driving licenses in this age group in the southeastern region of Norway.

A fatal outcome occurred in $22(15 \%)$ of the 145 drivers, serious nonfatal injuries (AIS score $\geq 2)$ occurred in 60 $(41 \%)$, and only minor injuries (AIS $<2$ ) occurred in $59(41 \%)$. Four drivers were injured and survived, but information on the injury outcome was missing.

Most (90\%) of the MVCs occurred on rural roads, and the vast majority (97\%) occurred on roads without barriers between opposing lanes. MVCs were more common during summer (32\%, vs $20 \%$ during winter months), at nighttime between 0000 and 0600 hours (35\%, vs $14 \%$ between 0600 and 1200 hours), and on roads with good road visibility (92\%) and no precipitation (80\%). Most of the MVs were regular passenger cars (88\%) (Table 1). The median MV age at the time of the collision was 14 years (range $0-40$ years). Single-vehicle collisions constituted more than half (58\%) of the total number of MVCs. In multivehicle collisions, passenger cars were the most common type of collision partner.

\section{Culpability and collision reasons}

Most ( $92 \%, n=133)$ of the drivers were considered culpable of the collision (culpability scores $\leq 13$ ), only in $8 \%$ of the cases the incident had likely been caused by the maneuver of the collision partner. Of the 12 nonculpable drivers, two drivers initially had scores of $\geq 15$ and ten drivers had intermediate scores of 13 or 14 . We identified the ten intermediate cases, discussed them, and arrived at a consensus opinion. All of the ten intermediate cases had two or more mitigating factors present, and the drivers were exonerated fully from culpability and therefore deemed nonculpable in the present study.

In comparison to nonculpable drivers, culpable drivers were more often younger than 21 years $(66 \%$ [88/133] vs $33 \%[4 / 12], p=0.031)$ and had obtained their driving license less than 2 years previously (68\% [69/101] vs $20 \%$ [2/10], $p=0.004)$. Most (77\%) of the culpable drivers were males. Culpable male drivers reported more often that they had been involved in a previous MVC compared to female drivers (32\% [24/74] vs 9\% [2/22], $p=$ 0.032). 
The critical events leading to the collision based on the collision investigations are given in Table 2, alongside what the drivers self-reported. The objective investigations disclosed that speeding - including reckless driving behavior and driving too fast for the road conditions - was the main cause of $80 \%$ of the MVCs among culpable drivers. Speeding was more common when carrying passengers than for solo driving (89\% [56/63] vs 73\% [51/70], $p=0.02)$ and more common in single-vehicle than multivehicle collisions ( $87 \%$ [74/85] vs $67 \%$ [32/48], $p=0.005$ ). The median changes in velocity ( $\Delta V$ values) were $57 \mathrm{~km} / \mathrm{h}$ (range $4-140 \mathrm{~km} / \mathrm{h}$ ) and $54 \mathrm{~km} / \mathrm{h}$ (range $9-108 \mathrm{~km} / \mathrm{h}$ ) for culpable and nonculpable drivers, respectively.

Almost half (46\%) of the surviving culpable drivers stated that their driving maneuvers had led to the collision, directly or indirectly, due to inattention, speeding, influence of alcohol or drugs, cell phone use, or simply losing control of the vehicle (Table 2). The information obtained from witnesses indicated that $8 \%$ of the culpable drivers (11/133) had fallen asleep immediately preceding the collision.

Thirty-two percent (29/92) of the culpable drivers reported that the purpose of the driving trip that ended with a collision was related to partying or cruising, and 21\% (20/94) reported playing loud music in the vehicle. Furthermore, $52 \%$ (37/71) reported that they had previous experience with driving faster than $150 \mathrm{~km} / \mathrm{h}$ on public roads. None of these factors were self-reported by the nonculpable drivers.

\section{Alcohol and/or drug impairment}

Information on driving under the influence (DUI) of alcohol and/or drugs existed in $96 \%$ (139/145) of the cases. It was concluded that DUI was likely in $34(27 \%)$ of the 127 culpable drivers and none of the 12 nonculpable drivers $(p=0.039)$. Of the likely DUI drivers, $79 \%(27 / 34)$ were confirmed by blood analysis. Blood analysis showed alcohol to be the most common detected toxicological substance $(85 \%, 23 / 27)$, followed by illicit drugs $(15 \%, 4 / 27)$; of which two drivers had THC-levels only and the other two drivers had both THC-levels and MDMA-levels above threshold limits). No occupants tested positive for both alcohol and drugs. Furthermore, $24 \%(24 / 100)$ of the culpable drivers self-reported previous experiences with DUI.

Compared to culpable sober drivers, DUI drivers were more often unrestrained by seatbelts $(62 \%$ [21/34] vs $84 \%$ [78/93], $p=0.008)$, involved in MVCs occurring between midnight and 0600 hours $(62 \%$ [21/34] vs $29 \%$ [27/93], $p=0.001)$, during summer months $(68 \%$ [23/34] vs $44 \%$ [41/93], $p=0.019)$, and single vehicle collisions $(77 \%[26 / 34]$ vs $57 \%$ [53/93], $p=0.045)$. A nonsignificant tendency was observed between DUI and speeding $(91 \%$ [31/34] vs 76\% [71/93], $p=0.063)$.

\section{Use of seatbelts}

Seventy-seven percent (103/133) of the culpable drivers were wearing a seatbelt at the time of the collision. Seatbelt use was less common during the nighttime ( 0000 to 0600 hours) compared to the rest of the day (67\% [32/48] vs $84 \%$ [71/85], $p=0.025)$, in single-vehicle collisions than multivehicle collisions $(71 \%$ [60/84] vs $88 \%[43 / 49], p=0.030)$, and among drivers aged $21-24$ years compared to those aged $18-20$ years $(83 \%$ [73/88] vs $67 \%$ [30/45], $p=0.033)$.

\section{Discussion}

This study has provided updated data on the involvement of young drivers in MVCs that lead to occupant injury in the southeastern region of Norway. The estimated rate of serious injury-causing collision involvement of 29 per 100,000 drivers aged 18-24 is lower than expected, but reflects the large reduction in the number of severe injuries and fatalities observed during the last decade for all occupants on Norwegian roads. The rate does not include all high-energy MVCs, instead only collisions resulting in hospital admissions. Improved vehicle safety and road standards are probably the main reasons for the reduction.

The main finding of this study is that the vast majority (92\%) of young drivers involved in injury-causing MVCs are themselves culpable of the collision. The critical factors leading to collisions are largely speeding and other driver-related errors, with environmental and vehicle factors contributing only sporadically. Our results support the existing body of evidence for young drivers involved in MVCs that underline the importance of unsafe 
speeds (McKnight and McKnight 2003). Overall, speeding is widespread and has remained one of the road safety problems most resistant to change (Elvik 2010); it increases the risk of fatal injuries and also the risk of being involved in a collision in the first place. Curry et al. showed that recognition errors such as lack of surveillance and distractions were the most important cause for young drivers colliding in the US, but speeding was probably the main underlying factor (Curry et al. 2011). Often there are several contributing factors leading to the collision. Some factors, such as driver attention deficits and distractions, may be difficult to establish with certainty unless video recordings of the collision exist or digital data on cell phone use are analyzed. Road traffic surveys from Norway have shown that the percentage of drivers speeding increased by nearly $50 \%$ from 1971 to 2004-2006 (Elvik 2010). The finding of the present study that speeding is a critical reason in $80 \%$ of collisions caused by young adults emphasizes that speeding must be a major focus in future prevention campaigns targeted at young drivers.

Collision culpability was associated with being younger than 21 years and holding a license for a short period. Several reports have shown an increased risk of culpability among young drivers (Poulsen, Moar, and Pirie 2014; Drummer et al. 2020) and that collision rates vary with both the experience acquired through the amount of driving, as well as maturity reckoned in terms of age (McKnight and McKnight 2003; McCartt et al. 2009). The available evidence indicated a steep learning curve among drivers of all ages, and particularly teenagers, and that the lengths of license-holding and driving experience were of more importance than age (McCartt et al. 2009). A driving license can be acquired at the age of 18 years in Norway, as in most European countries. Staged licensing systems for young drivers, such as limiting inexperienced young drivers from driving unsupervised at night, have been introduced in other countries with the aim of reducing collision rates. Our data support that this also could have a positive effect in Norway.

Nonculpable drivers are assumed to be randomly involved in collisions determined by external factors. If the criterion used to assign culpability in a sample is correct, it can be expected that all variables other than risk exposure will be very similar among nonculpable drivers (Brubacher, Chan, and Asbridge 2012). Indeed, we observed that risk factors associated with colliding (e.g., alcohol or drug use, speeding, being young and male, and driving inexperience) were significantly associated with culpability. Nevertheless, designated as nonculpable do not remove all opportunity to avoid the collision, as such drivers may have failed to respond successfully to conflicts created by the unexpected actions of other drivers (McCartt et al. 2009).

We found major variations between what the drivers self-reported and what our objective investigations disclosed as reasons for collisions. Recall bias may partly explain the discrepancy, but a more-likely reason is concern about legal allegations, even though full secrecy was assured in this study. A recent self-report study demonstrated that age and demographic factors appear to have more influence on driving behavior than knowledge of traffic rules. Factors such as risk perception, observed road misbehavior of parents and peers, and their attitudes towards traffic safety tend to affect young drivers' risky behavior and road safety outcomes (Alonso et al. 2018).

As expected, there was a male predominance among culpable drivers. Previous studies have indicated that young male drivers are more likely to be involved in collisions due to speeding and more often drive at speeds that are unsafe for the conditions compared to young female drivers (McKnight and McKnight 2003; Simons-Morton, Lerner, and Singer 2005). Interestingly, we found that speeding was not limited to male drivers, but observed also among $71 \%$ of culpable female drivers. Although limited by the relatively small numbers of subjects, the data suggest that neither speeding nor DUI is restricted to males. However, the greater involvement of male drivers in previous MVCs compared to female drivers shows that there are probably some sex-related differences with regard to learning and age-dependent risk-taking behaviors.

It is well documented that alcohol consumption increases the collision risk for drivers of all ages (Harrison and Fillmore 2005), but in particular for young drivers (Voas et al. 2012). There are reports that cannabis and other illicit drugs also may play a significant role (Valen et al. 2017; Drummer et al. 2020), but this study indicates that alcohol is the main problem on Norwegian roads when it comes to young drivers culpable of injury-causing MVCs. In a previous study of driver fatalities from 2000 to 2014, we detected toxicological substances in 39\% of drivers aged 18-25 years, and this was most commonly alcohol, whereas illicit or medical drugs were more 
common in older drivers. DUI was associated with collisions occurring during the nighttime and not using a seatbelt at the time of the collision (Breen et al. 2018). This might represent a group exhibiting pronounced risktaking behaviors combining reckless driving with alcohol abuse. It has been reported that persistent traffic offenders differ from nonoffenders in their alcohol consumption, propensity for law-breaking, driving styles, sociodemographic factors, and personality traits. Recidivist traffic offenders showed more often problematic alcohol habits, sensation seeking behavior and propensity to get angry while driving than nonoffenders (MartiBelda et al. 2019).

It has been claimed that distractions caused by cell phone use significantly contribute to MVCs for novice and young drivers (Llerena et al. 2015). A collision-culpability analysis comparing collisions involving and not involving cell phones found that the odds of a culpable collision was increased by $70 \%$ when a cell phone was used by drivers of any age (Asbridge, Brubacher, and Chan 2013). We found that only $4 \%$ of the culpable drivers stated that the collision was caused by distraction due to using a cell phone when driving. Our findings are based on self-reporting and may be an underestimate of the role of cell phone use.

\section{Limitations}

This is a prospective, observational cross-sectional study, with subordinate case-control analyses between culpable and nonculpable drivers. The inclusion of a small control group of only 12 nonculpable drivers limits the power of the statistical analyses performed in this study. Also, data were not collected for a non-collisioninvolved comparison group, precluding the interpretation of collision circumstances as collision risk factors. These limitations mean that the related results should be interpreted cautiously.

Examining real-world MVCs is challenging. Data collection and particularly the assessment of collision causation are both influenced by the established theoretical and practical framework of collision investigation and personal know-how. To minimize the subjectivity, multiple stages of quality control were implemented. Onscene collection of collision data was systematically and prospectively performed by experienced and welltrained individuals. Data obtained from various sources were compared and reviewed by a multidisciplinary team and scored in a uniform manner, thus reducing the interrater variability.

We cannot guarantee that all relevant MVCs that occurred during the study period were reported to us, although this is highly unlikely. The EMCCs were trained about alerting the collision investigation teams from a previous study with similar design (Skjerven-Martinsen et al. 2014). Our checking of daily news updates did not reveal any MVCs additional to those reported by the EMCCs. From experience we know that some collisions, even those occurring at high speeds, may occur without the involvement of authorities. It is nevertheless unlikely that there were many such events that resulted in serious occupant injury which we were not alerted about. Severe injury almost always manifests itself in the early course. Injured occupants with delay in seeking health-care would be referred to a trauma hospital if their injury was severe, in which case we would be alerted by the EMCCs.

\section{Acknowledgements}

The project was supported financially by the Gjensidige Foundation and the Norwegian Ministry of Transport and Communication. The authors acknowledge the region's five EMCCs (in Oslo/Akershus, Innlandet, Drammen, Kristiansand, and Tønsberg), the police districts of southeastern Norway for their valuable cooperation, and paramedics Kim Ankersten and Geir Engely for data collection. 


\section{References}

Alonso F, Esteban C, Useche S, Colomer N. Effect of Road Safety Education on Road Risky Behaviors of Spanish Children and Adolescents: Findings from a National Study. Int J Environ Res Public Health, 2018;15(12).

Asbridge M, Brubacher JR, Chan H. Cell phone use and traffic crash risk: a culpability analysis. Int J Epidemiol. 2013;42: 259-67.

Breen JM, Naess PA, Gjerde H, Gaarder C, Stray-Pedersen A. The significance of preexisting medical conditions, alcohol/drug use and suicidal behavior for drivers in fatal motor vehicle crashes: a retrospective autopsy study. Forensic Sci Med Pathol. 2018;14(1):4-17.

Brubacher J, Chan H, Asbridge M. Development and validation of a crash culpability scoring tool. Traffic Inj Prev. 2012;13(3):219-229.

Curry AE, Hafetz J, Kallan MJ, Winston FK, Durbin DR. Prevalence of teen driver errors leading to serious motor vehicle crashes. Accid Anal Prev. 2011;43(4):1285-1290.

Drummer, OH, Gerostamoulos D, Di Rago M, Woodford NW, Morris C, Frederiksen T, Jachno K, Wolfe R. Odds of culpability associated with use of impairing drugs in injured drivers in Victoria, Australia. Accid Anal \& Prev. 2020;135:105389.

Elvik R. Why some road safety problems are more difficult to solve than others. Accid Anal Prev. 2010;42(4):1089-1096.

Harrison EL, Fillmore MT. Are bad drivers more impaired by alcohol? Sober driving precision predicts impairment from alcohol in a simulated driving task. Accid Anal Prev. 2005;37(5):882-889.

Llerena LE, Aronow KV, Macleod J, Bard M, Salzman S, Greene W, Haider A, Schupper A. 2015. An evidencebased review: distracted driver. J Trauma Acute Care Surg. 2015;78(1):147-152.

Marti-Belda A, Pastor J, Montoro L, Boso P. Persistent Traffic Offenders: Alcohol Consumption and Personality as Predictors of Driving Disqualification. The European Journal of Psychology Applied to Legal Context, 2019;11:81-92.

McCartt AT, Mayhew DR, Braitman KA, Ferguson SA, Simpson HM. Effects of age and experience on young driver crashes: review of recent literature. Traffic Inj Prev. 2009;10(3):209-219.

McKnight AJ, McKnight AS. Young novice drivers: careless or clueless? Accid Anal Prev. 2003;35(6):921-925.

Nordbakke S, Sagberg F, Gregersen F. The end of passion? Changes in driving license rate and driving rate among young people. Oslo: The Institute of Transport Economics. 2016. 52p. Rep. No.: 1477/2016.

Poulsen H, Moar R, Pirie R. The culpability of drivers killed in New Zealand road crashes and their use of alcohol and other drugs. Accid Anal Prev. 2014;67:119-128.

Robertson MD, Drummer OH. Responsibility analysis: a methodology to study the effects of drugs in driving. Accid Anal Prev. 1994;26(2):243-247.

Simons-Morton B, Lerner N, Singer J. The observed effects of teenage passengers on the risky driving behavior of teenage drivers. Accid Anal Prev. 2005;37: 973-82.

Skjerven-Martinsen M, Naess PA, Hansen TB, Gaarder C, Lereim I, Stray-Pedersen A. A prospective study of children aged $<16$ years in motor vehicle collisions in Norway: severe injuries are observed predominantly in older children and are associated with restraint misuse. Accid Anal Prev. 2014;73: 151-62.

Statistics-Norway. Persons killed or injured in road accidents 2000-2012 [Veitrafikkulykker Med Personskade]. Oslo, Norway. 2012. Available at http://www.ssb.no/statbank/sq/10018813/. Accessed May 18, 2019.

Valen A, Bogstrand ST, Vindenes V, Gjerde H. Increasing use of cannabis among arrested drivers in Norway. Traffic Inj Prev. 2017;1-6.

Voas RB, Torres P, Romano E, Lacey JH. Alcohol-related risk of driver fatalities: an update using 2007 data. $J$ Stud Alcohol Drugs. 2012;73(3):341-350.

World Health Organization. Global Staus Report on Road Safety. Geneva (Switzerland): World Health Organization; 2018. Licence: CC BY-NC-SA 3.0 IGO. 
Table 1: Vehicle and collision types

Multivehicle collisions

MVs approaching in opposite lanes

MVs on roundabouts

MVs colliding in the same lane

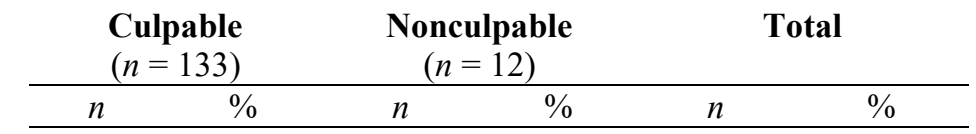

Single-vehicle collisions

MVs driving off the road in a curve

MVs driving off a straight road

MV type

Sedan/station wagon/hatchback

Sports utility vehicle/van

Lorry/truck/bus

MV type of collision partner

Sedan/station wagon/hatchback

Sports utility vehicle/van

Lorry/truck/bus

$\begin{array}{cccccc}43 & 88^{*} & 5 & 42 & 48 & 79 \\ 2 & 4 * & 3 & 25 & 5 & 8 \\ 4 & 8 * & 4 & 33 & 8 & 13\end{array}$

MV impact area

$\begin{array}{lcc}\text { Front } & 80 & 60 \\ \text { Side } & 20 & 15 \\ \text { Rear } & 3 & 2^{*} \\ \text { Rollover } & 30 & 23\end{array}$

\begin{tabular}{cccccc}
51 & $61 *$ & 0 & 0 & 51 & 61 \\
33 & 39 & 0 & 0 & 33 & 39 \\
117 & 88 & 11 & 92 & 128 & 88 \\
15 & 11 & 1 & 8 & 16 & 11 \\
1 & 1 & 0 & 0 & 1 & 1 \\
& & & & & \\
26 & 54 & 5 & 42 & 31 & 52 \\
8 & 17 & 5 & 42 & 13 & 22 \\
14 & 29 & 2 & 17 & 16 & 27 \\
& & & & & \\
80 & 60 & 8 & 67 & 88 & 61 \\
20 & 15 & 0 & 0 & 20 & 14 \\
3 & $2 *$ & 4 & 33 & 7 & 5 \\
30 & 23 & 0 & 0 & 30 & 21 \\
110 & 83 & 8 & 67 & 118 & 81 \\
23 & 17 & 4 & 33 & 27 & 19 \\
\hline
\end{tabular}

Vehicle age $\geq 10$ years

\begin{tabular}{lccc} 
Yes & 110 & 83 & 8 \\
No & 23 & 17 & 4 \\
\hline
\end{tabular}

*Significantly different $(p<0.05)$ compared to nonculpable drivers (reference group)

Table 2: Critical reasons for collision from objective investigations and self-reporting

\begin{tabular}{lll}
\hline Collision investigation of culpable drivers $(\boldsymbol{n}=\mathbf{1 3 3})$ & $\boldsymbol{n}$ & \% of total \\
\hline Exceeding the posted speed limit & 59 & 44 \\
Reckless driving & & 15 \\
Driving too fast for road conditions & 33 & 25 \\
Performance/handling errors or inattention in response to traffic event ${ }^{\mathrm{b}}$ & 24 & 18 \\
Poor road/weather conditions and/or vehicle failure & 2 & 2
\end{tabular}

\begin{tabular}{lll}
\hline Self-reports of culpable drivers $(\boldsymbol{n}=\mathbf{9 2})^{\mathbf{c}}$ & $\boldsymbol{n}$ & \% of total \\
\hline Poor road conditions & 22 & 24 \\
Inattention & 13 & 14 \\
Speeding & 10 & 11 \\
Alcohol/drug use & 8 & 9 \\
Lost control of vehicle & 7 & 8 \\
Events outside my control (animals or other driving hazards) & 6 & 6 \\
Cell phone use & 4 & 4 \\
Vehicle technical error & 2 & 2 \\
No memory of cause & 20 & 22 \\
\hline
\end{tabular}

${ }^{a}$ Traveling $>30 \mathrm{~km} / \mathrm{h}$ faster than posted speed limit and/or hazardous overtaking

${ }^{\mathrm{b}}$ Including avoiding animals and bumps on the road and partner vehicle stopping abruptly

${ }^{\mathrm{c}}$ Total number differs since current information was missing in several cases 


\section{Appendix - Supplementary material}

Figure A1: Study outline.

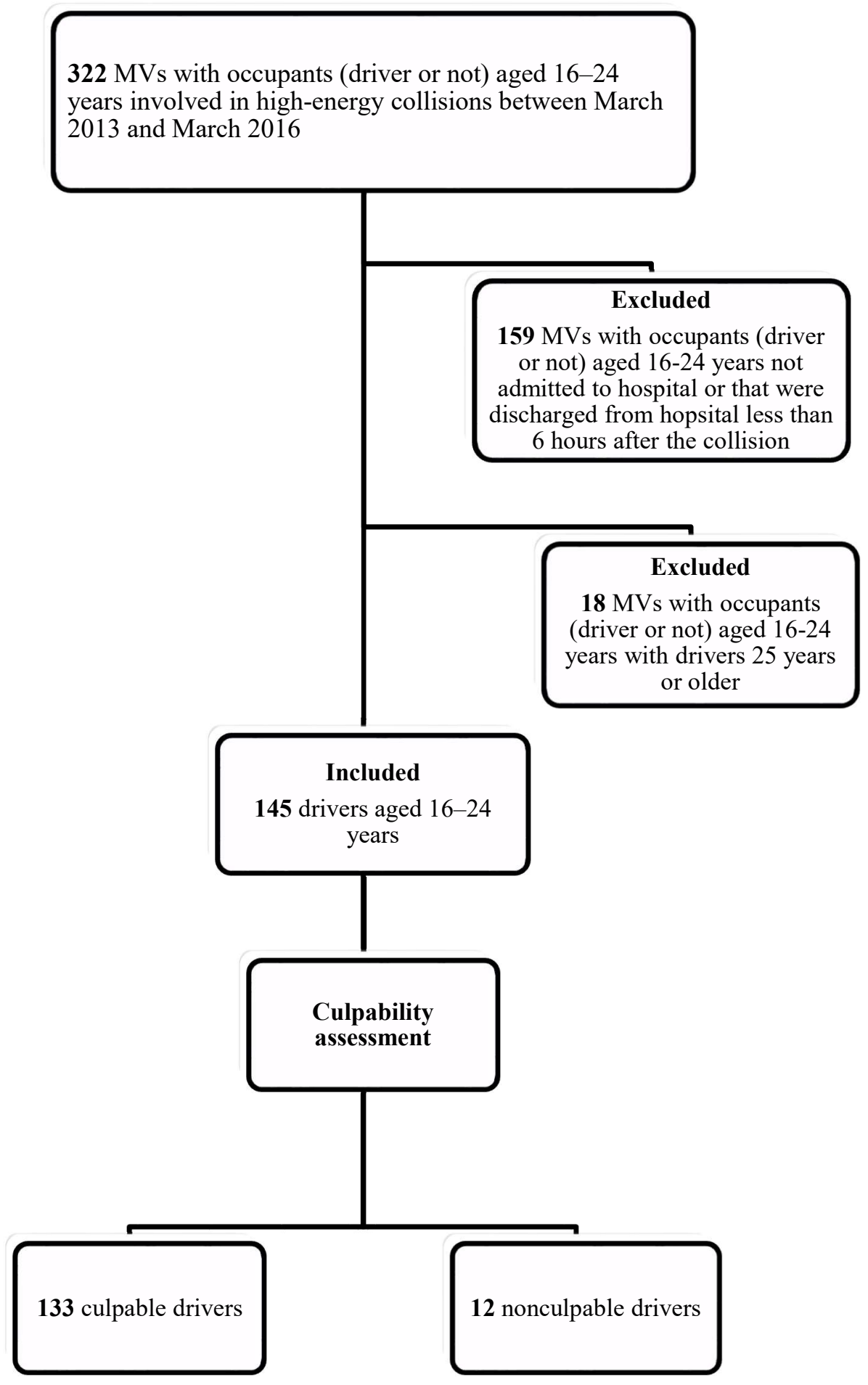


Table A1: Characteristics related to the driver and the current driving trip

Gender

Male

Female

Age

$$
\begin{aligned}
& 16-17 \text { years } \\
& 18-20 \text { years } \\
& 21-24 \text { years }
\end{aligned}
$$

Duration of driving license $\mathrm{a}^{\mathrm{a}}$

No/invalid driving license

$\leq 6$ months

$>6$ months to 1 year

$>1$ year to 2 years

$>2$ years

Speeding (exceeding posted speed limit, driving

too fast for conditions, or driving hazardously)

Yes

No

Driving under the influence of alcohol/drugs

Yes
No

Use of a seatbelt

No

Yes

Outcome for driver

Fatal injury

Nonfatal, severe injury (AIS score $\geq 2$ )

Nonfatal, minor injury (AIS score $=0 / 1$ )

Nonfatal, AIS score unknown

Driver involved in previous $\mathrm{MVC}^{\mathrm{a}, \mathrm{b}}$

Yes

No

Driver reported previously driving faster than

$150 \mathrm{~km} / \mathrm{h}$ ) on public roads ${ }^{\mathrm{a}, \mathrm{b}}$

Yes

No

Purpose of the driving trip ${ }^{\mathrm{a}, \mathrm{b}}$

Socializing with family/friends

Related to job/school

Partying/cruising

Other

Mileage of the current driving trip before the collision $^{\mathrm{a}, \mathrm{b}}$

$$
\begin{aligned}
& 0-24 \mathrm{~km} \\
& 25-49 \mathrm{~km} \\
& 50-99 \mathrm{~km} \\
& \geq 100 \mathrm{~km}
\end{aligned}
$$

Presence of youth passengers

$$
\text { No }
$$$$
\text { Yes }
$$

\begin{tabular}{cc}
\multicolumn{2}{c}{$\begin{array}{c}\text { Culpable } \\
(\mathrm{n}=133)\end{array}$} \\
\hline$n$ & $\%$ \\
\hline & \\
102 & 77 \\
31 & 23 \\
& \\
4 & 3 \\
84 & 63 \\
45 & $34^{*}$
\end{tabular}

Nonculpable

$(n=12)$

$\%$

6

50

50

Total

$(n=145)$

$\%$

108

$\begin{array}{ccc}4 & 4 & 0 \\ 40 & 38 & 2 \\ 10 & 10 & 0 \\ 19 & 18 & 0 \\ 32 & 30^{*} & 8\end{array}$

0

$$
\begin{gathered}
0 \\
33
\end{gathered}
$$

$27 \quad 20$

53

$\begin{array}{lll}80 & 40 & 35\end{array}$

$\begin{array}{cccccc}34 & 27 & 0 & 0 & 34 & 24 \\ 93 & 73 & 12 & 100 & 105 & 76\end{array}$

$\begin{array}{llllll}30 & 23 & 1 & 8 & 31 & 21\end{array}$

$\begin{array}{llllll}103 & 77 & 11 & 92 & 114 & 79\end{array}$

$\begin{array}{llllll}20 & 51 & 2 & 17 & 22 & 15\end{array}$

$56 \quad 42$

43

50

4

$\begin{array}{llllll}70 & 73 & 7 & 78 & 77 & 73\end{array}$

$\begin{array}{llllll}37 & 52 & 0 & 0 & 37 & 50\end{array}$

$\begin{array}{llllll}34 & 48 & 3 & 100 & 37 & 50\end{array}$

$\begin{array}{llllll}42 & 45 & 5 & 56 & 47 & 46\end{array}$

$\begin{array}{llllll}42 & 45 & 5 & 56 & 47 & 46 \\ 14 & 15 & 2 & 22 & 16 & 16\end{array}$

$\begin{array}{cccccc}19 & 31 & 0 & 0 & 29 & 28\end{array}$

$\begin{array}{llllll}9 & 10 & 2 & 22 & 11 & 11\end{array}$

50

$\begin{array}{llllll}64 & 68 & 5 & 56 & 69 & 67 \\ 10 & 11 & 1 & 11 & 11 & 11 \\ 10 & 11 & 2 & 22 & 12 & 12 \\ 10 & 11 & 1 & 11 & 11 & 11\end{array}$

AIS, Abbreviated Injury Scale

*Significantly different $(p<0.05)$ compared to nonculpable drivers (reference group)

${ }^{\text {a }}$ Total number differs since current information was missing in several cases 
${ }^{\mathrm{b}}$ Self-reported by the drivers

Table A2: Road type and conditions at the time of the collision

Season

Winter (December to February)

Spring (March to May)

Summer (June to August)

Autumn (September to

November)

Time of day

0000-0600 hours

0600-1200 hours

1200-1800 hours

1800-2400 hours

Area

Urban

Rural

Road topography

Curved

Straight

Road visibility

Good

$\mathrm{Bad}$

Lighting conditions

Daylight or road lighting

Twilight or darkness

Precipitation

None

Rain/snow

Road surface

Dry asphalt

Wet/icy asphalt

Posted speed limit

$\leq 50 \mathrm{~km} / \mathrm{h}$

$60 \mathrm{~km} / \mathrm{h}$

$70 \mathrm{~km} / \mathrm{h}$

$80 \mathrm{~km} / \mathrm{h}$

$\geq 90 \mathrm{~km} / \mathrm{h}$

Barriers between opposing lanes

Yes

No

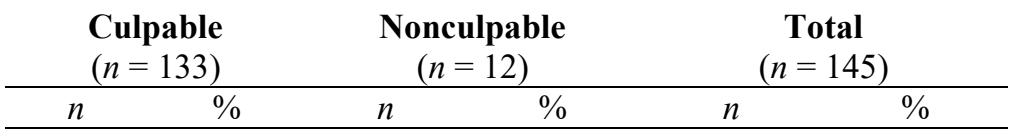

$\begin{array}{llllll}27 & 20 & 2 & 17 & 29 & 20 \\ 29 & 22 & 4 & 33 & 33 & 23 \\ 44 & 33 & 3 & 25 & 47 & 32 \\ 33 & 25 & 3 & 25 & 36 & 25\end{array}$

$48 \quad 36$

$17 \quad 13$

$34 \quad 26$

$34 \quad 26$

$14 \quad 11$

$119 \quad 89$

80

53

60

40

122

11

92

$87 \quad 65$

$46 \quad 35$

$108 \quad 81$

25

19

$77 \quad 58$

$56 \quad 42$

$20 \quad 15$

$36 \quad 27$

$15 \quad 11$

$57 \quad 43$

54

$\begin{array}{cc}3 & 2 \\ 130 & 98\end{array}$

$\begin{array}{lll}25 & 51 & 35 \\ 25 & 20 & 14 \\ 25 & 37 & 26 \\ 25 & 37 & 26\end{array}$

10

90

130

59

$50 \quad 59$

92

8

68

$\begin{array}{lll}67 & 116 & 80\end{array}$

$29 \quad 20$

$85 \quad 59$

$60 \quad 41$

$33 \quad 60$

41

$\begin{array}{lll}8 & 21 & 14\end{array}$

$\begin{array}{lll}25 & 39 & 27\end{array}$

$\begin{array}{lll}8 & 16 & 11\end{array}$

$\begin{array}{lll}42 & 62 & 43\end{array}$

$\begin{array}{lll}17 & 7 & 5\end{array}$

$4 \quad 3$

$141 \quad 97$ 